\title{
Upregulation of maspin expression in human cervical carcinoma cells by transforming growth factor $\beta 1$ through the convergence of Smad and non-Smad signaling pathways
}

\author{
ARIYAPHONG WONGNOPPAVICH ${ }^{1}$, NAHATHAI DUKAEW ${ }^{1}$, \\ SIRINTHIP CHOONATE ${ }^{2}$ and KONGTHAWAT CHAIRATVIT ${ }^{2}$ \\ ${ }^{1}$ Department of Biochemistry, Faculty of Medicine, Chiang Mai University, Chiang Mai 50200; \\ ${ }^{2}$ Department of Oral Biology, Faculty of Dentistry, Mahidol University, Bangkok 10400, Thailand
}

Received April 4, 2016; Accepted January 31, 2017

DOI: $10.3892 / \mathrm{ol} .2017 .5939$

\begin{abstract}
Mammary serine protease inhibitor (maspin), encoded by the serpin family B member 5 gene, serves as a tumor suppressor through the inhibition of cancer cell invasion and metastasis. Paradoxically, maspin levels are upregulated in a number of types of malignant cells. Therefore, the regulation of maspin expression may depend on the genetic or epigenetic background and the specific microenvironment of carcinoma cells. In the present study, it was demonstrated that transforming growth factor $\beta 1$ (TGF- $\beta 1$ ) induced maspin expression at the transcript and protein levels in the human cervical carcinoma HeLa and human oral squamous carcinoma HSC4 cell lines. The inhibition of the mothers against decapentaplegic homolog (Smad)-dependent pathway by a Smad3-specific inhibitor suppressed maspin induction by TGF- $\beta 1$ in HeLa cells. Inhibition of the non-Smad pathway by pretreatment with the mitogen-activated protein kinase kinase 1/2 (MEK1/2) inhibitor U0126, or the p38 mitogen-activated protein kinase (p38 MAPK) inhibitor SB202190, attenuated the effect of TGF- $\beta 1$ on maspin upregulation, whereas pretreatment with pyrrolidine dithiocarbamate (a nuclear factor $\kappa \mathrm{B}$ inhibitor), wortmannin (a phosphoinositide 3-kinase inhibitor) or SP600125 (a c-Jun N-terminal kinase inhibitor) did not. Notably, none of these inhibitors eliminated the TGF- $\beta 1$-induced phosphorylation of Smad2. In addition, mutations at $\mathrm{p} 53$-binding sites in the maspin promoter suppressed TGF- $\beta 1$-induced maspin expression, indicating the necessity of intact p53-binding sites on the maspin promoter. In summary, the induction of maspin expression in HeLa cells
\end{abstract}

Correspondence to: Dr Kongthawat Chairatvit, Department of Oral Biology, Faculty of Dentistry, Mahidol University, 6 Yothee Road, Bangkok 10400, Thailand

E-mail: kongthawat.cha@mahidol.ac.th

Key words: cervical carcinoma, mothers against decapentaplegic homolog, non-Smad signaling, serpin family B member 5, tumor protein $\mathrm{p} 53$, transforming growth factor $\beta 1$ requires the convergence of TGF- $\beta 1$-induced Smad and non-Smad signaling pathways, in which the latter acts via the intermediate signaling molecules MEK1/2 and p38 MAPK.

\section{Introduction}

Mammary serine protease inhibitor (maspin), encoded by the serpin family $\mathrm{B}$ member 5 gene, belongs to the serine protease inhibitor superfamily of proteins (1). Several studies have revealed that maspin is an effective inhibitor of cancer cell invasion, metastasis and angiogenesis (2). Maspin was originally identified in normal mammary epithelial cells, and is reduced or absent in carcinoma (3). The induction of maspin gene expression in carcinoma cell lines leads to an inhibition of cell invasion and metastasis in vitro and in vivo (4). Therefore, maspin possesses potential as a target for the prognosis and diagnosis of and therapeutic intervention against cancer.

The regulation of maspin expression in cancer cells is tissue-specific. Maspin was originally identified as a tumor suppressor due to its high expression level in normal breast and prostate, and low or absent expression levels in malignancies $(5,6)$. Paradoxically, the expression of maspin is maintained during carcinogenesis in a number of tissue types, including ovarian, lung and pancreatic tissues (7-9). Additionally, the overexpression of maspin has also been detected in inflammatory bowel disease (10), and a high incidence of aberrant maspin expression is associated with intestinal metaplasia and carcinoma of the gall bladder (11).

The growth and invasion of transformed cells in tumors are often accompanied by inflammation, as immune cells and macrophages are recruited to the tumor site and release pro-inflammatory cytokines, including interleukin-6 (IL-6), transforming growth factor $\beta 1$ (TGF- $\beta 1$ ) and tumor necrosis factor $\alpha$ (TNF- $\alpha)$ (12). A number of inflammatory cytokines exert tumor suppressive properties against cells at the early stages of tumorigenesis, but become tumor inducers at the later stages of cancer progression (13). Depending upon the stage of carcinogenesis, the effects of these cytokines vary according to the signaling pathways activated. TGF- $\beta 1$ stimulates signaling responses via mothers against decapentaplegic homolog (Smad) and non-Smad signaling pathways $(14,15)$. 
Upon activation by TGF- $\beta 1$, Smad 2 and Smad 3 become phosphorylated and form complexes with Smad4, which in turn regulate the transcription of target genes. In the latter pathway, TGF- $\beta 1$ signaling can occur via several adapter proteins, such as p38 mitogen-activated protein kinase (p38 MAPK), Erk MAP kinases, phosphoinositide-3-kinase (PI3Kinase)/Akt, and c-Jun N-terminal kinases (JNK) (15).

Previous research has suggested that TGF- $\beta 1$ serves a role in several processes of carcinogenesis, including invasion, migration, mesenchymal transition and extracellular matrix synthesis, in a number of cancer cell types (16). Therefore, changes in maspin expression may be associated with the inflammatory responses mediated by TGF- $\beta 1$, leading to the progression from hyperplasia to neoplasia. Overexpression of TGF- $\beta 1$ within the tumor microenvironment may increase the metastatic potential of various types of tumor (17).

Maspin promoters contain Smad-and p53-binding elements, which are required for the upregulation of the maspin gene by TGF- $\beta 1$ in normal mammary epithelial cells (18). In the present study, the effects of TGF- $\beta 1$ and the pro-inflammatory cytokines TNF- $\alpha$ and IL- 6 on maspin expression in human cervical HeLa and oral squamous carcinoma HSC4 cell lines were investigated.

\section{Materials and methods}

Cell cultures. The human cervical carcinoma HeLa and oral squamous carcinoma HSC4 cell lines were provided by the Institute of Biotechnology and Genetic Engineering, Chulalongkorn University (Bangkok, Thailand) and Associate Professor R. Surarit of Mahidol University (Bangkok, Thailand), respectively. The cell cultures were maintained in Dulbecco's modified Eagle's medium (DMEM; Invitrogen; Thermo Fisher Scientific, Inc., Waltham, MA, USA) supplemented with $10 \%$ heat-inactivated fetal bovine serum (FBS; Hyclone; GE Healthcare Life Sciences, Logan, UT, USA) and $1 \mathrm{X}$ antibiotic-antimycotic solution (Invitrogen; Thermo Fisher Scientific, Inc.) at $37^{\circ} \mathrm{C}$ in an atmosphere of $5 \% \mathrm{CO}_{2}$.

Reverse transcription-quantitative polymerase chain reaction ( $q P C R$ ). Total RNA was extracted using TRIzol reagent (Invitrogen; Thermo Fisher Scientific, Inc.). A total of $1 \mu \mathrm{g}$ RNA was treated with DNase (Invitrogen; Thermo Fisher Scientific, Inc.) and then the half amount of DNase-treated RNA was converted into complementary DNA (cDNA) using oligo-(dT) $)_{18}$ and a RevertAid ${ }^{\mathrm{TM}}$ First Strand cDNA Synthesis kit (Fermentas; Thermo Fisher Scientific, Inc.). The reverse transcription reaction was carried out at $42^{\circ} \mathrm{C}$ for $60 \mathrm{~min}$. qPCR was then performed in an ABI 7500 Real-time PCR system (Applied Biosystems; Thermo Fisher Scientific, Inc.). Each reaction mixture contained $5 \mu \mathrm{l} \mathrm{cDNA}$ (diluted 1:5), $10 \mu \mathrm{l} 2 \mathrm{X}$ Maxima $^{\mathrm{TM}}$ SYBR-Green/ROX qPCR Master Mix (Fermentas; Thermo Fisher Scientific, Inc.) and $0.3 \mu \mathrm{M}$ primer pairs for maspin or GAPDH (internal control). The primer pairs were as follows: Maspin forward, 5'-CGTAGAAAACTAATCAAG CGGCTCTAG-3'; maspin reverse, 5'-CCAATTCCTTTGCAT AGGGTCTC-3'; GAPDH forward, 5'-CGTTGGGTGAAG GTCGGAGTCAAG-3'; and GAPDH reverse, 5'-GGCAAC AATATCCACTTTACCAGA-3'. The thermocycling conditions were as follows: $95^{\circ} \mathrm{C}$ for $10 \mathrm{~min}$; and 45 cycles of $95^{\circ} \mathrm{C}$ for $15 \mathrm{sec}$ and $60^{\circ} \mathrm{C}$ for $60 \mathrm{sec}$. Relative maspin expression levels were normalized to GAPDH and calculated using the $2^{-\Delta \Delta \mathrm{Cq}}$ method (19). All experiments were performed 3 times with 3 replicates per experiment.

Treatment of cell lines with cytokines and inhibitors. The cytokines TGF- $\beta 1$, TNF- $\alpha$ and IL-6 (Roche Diagnostics; Indianapolis, IN, USA) were added at $0.1,1$, or $10 \mathrm{ng} / \mathrm{ml}$ to cancer cells in serum-free DMEM and incubated at $37^{\circ} \mathrm{C}$ in an atmosphere of $5 \% \mathrm{CO}_{2}$ for $48 \mathrm{~h}$ or as indicated. Smad3 inhibitor (SIS3; Merck KGaA, Billerica, MA, USA; 1, 5 or $10 \mu \mathrm{M}$ ), $100 \mu \mathrm{M}$ pyrrolidine dithiocarbamate (PDTC; Sigma-Aldrich; Merck KGaA, Darmstadt, Germany), $1 \mu \mathrm{M}$ wortmannin (Sigma-Aldrich; Merck KGaA), $10 \mu \mathrm{M}$ SP600125 (Sigma-Aldrich; Merck KGaA), $10 \mu$ M U0126 (Sigma-Aldrich; Merck KGaA) or $10 \mu \mathrm{M}$ SB202190 (Merck KGaA) were incubated with confluent $\mathrm{HeLa}$ cells for $1 \mathrm{~h}$ at $37^{\circ} \mathrm{C}$ in a $5 \% \mathrm{CO}_{2}$ atmosphere. A total of $10 \mathrm{ng} / \mathrm{ml}$ TGF- $\beta 1$ was then added and the cells were incubated for an additional $48 \mathrm{~h}$.

Western blotting. Subsequent to the aforementioned treatments, cells were washed twice with cold PBS, lysed with a Mammalian Protein Extraction buffer (GE Healthcare Life Sciences, Piscataway, NJ, USA) containing a protease and phosphatase inhibitor cocktail (Roche Diagnostics), and centrifuged at $14,000 \times \mathrm{g}$ for $10 \mathrm{~min}$ at $4^{\circ} \mathrm{C}$. A total of $10 \mu \mathrm{g}$ of protein, measured using a Bio-Rad ${ }^{\mathrm{TM}}$ Protein Assay (Bio-Rad Laboratories, Inc., Hercules, CA, USA), were separated by $10 \%$ SDS-PAGE, then transferred onto a nitrocellulose membrane. The blot was incubated with 5\% non-fat dried milk in Tris buffer saline (TBS) with $0.01 \%$ Tween-20. Membranes were then treated with $0.5 \mu \mathrm{g} / \mathrm{ml}$ mouse monoclonal anti-human maspin (cat. no. 554292; BD Biosciences, San Jose, CA, USA), rabbit monoclonal anti-Smad2 (cat. no. \#3122; Cell Signaling Technology, Inc., Danvers, MA, USA; dilution 1:1,000), rabbit monoclonal anti-phospho-Smad2 (cat. no. \#8828; Cell Signaling Technology, Inc.; dilution, 1:2,000), mouse polyclonal anti-p38 mitogen-activated protein kinase (cat. no. \#9212; Cell Signaling Technology, Inc.; dilution, 1:2,000), or mouse polyclonal anti-phospho-p38 mitogen-activated protein kinase (p38 MAPK; cat. no. \#9211; Cell Signaling Technology, Inc.; dilution, 1:2,000) primary antibodies. Subsequently, the membranes were incubated with horseradish peroxidase-conjugated goat anti-mouse (cat. no. 1706516; dilution, 1:7,500; Bio-Rad Laboratories, Inc.) or goat anti-rabbit immunoglobulin G (cat. no. 1706515; dilution, 1:7500; Bio-Rad Laboratories, Inc.) secondary antibodies, and immunoreactive protein bands were visualized using Western Lightning ${ }^{\circledR}$ Plus-ECL substrate (PerkinElmer, Inc., Waltham, MA, USA). For normalization of protein loading, the blots were then stripped and re-probed with primary rabbit polyclonal anti-human actin antibodies (cat. no. \#A2066; Sigma-Aldrich; Merck KGaA; dilution, 1:1,000) as described previously. All experiments were performed 3 times with 3 replicates per experiment.

Transfection and luciferase reporter assay. A full-length maspin promoter in a luciferase reporter plasmid (pLightSwitch; Active Motif, Carlsbad, CA, USA) was used to generate two $5^{\prime}$ truncated maspin promoters (-600 maspin 
promoter and -300 maspin promoter) in a pLightSwitch luciferase reporter plasmid by a PCR-based method (20). Point mutations in two p53-binding sites, p53 I and p53 II, in the maspin promoter region were constructed using the QuickChange II Site-Directed Mutagenesis kit (Stratagene, La Jolla, CA, USA) and a pLightSwitch plasmid containing -300 maspin promoter as the template. A pair of primers, 5'-GCCCCTTCCTGCCCtatatacaacGAGGCCTTTTGGAAG C-3' and 5'-GCTTCCAAAAGGCCTCgttgtatataGGGCAGG AAGGGGC-3' (mutated nucleotides illustrated in lowercase letters), were used to introduce sequence substitution at the p53 I binding site. The primers for mutation of p53 II binding site were 5'-GCCGAGAGGATTGCCGTAatataGTCTGTA CGTATGCATG-3' and 5'-CATGCATACGTACAGACtata tTACGGCAATCCTCTCGGC-3'. The correct changes to the mutated sequences were confirmed by DNA sequencing at First BASE Laboratories (Selangor, Malaysia). Each construct was transfected into the HeLa cells using TurboFect ${ }^{\text {Tw }}$ in vitro Transfection Reagent (Fermentas; Thermo Fisher Scientific, Inc.) according to the manufacturer's protocol. After $4 \mathrm{~h}$ transfection, the medium was replaced with serum free-DMEM and the cells were incubated for a further $2 \mathrm{~h}$. The cells were then incubated with $10 \mathrm{ng} / \mathrm{ml}$ TGF- $\beta 1$, or without TGF- $\beta 1$ as control, at $37^{\circ} \mathrm{C}$ in a $5 \% \mathrm{CO}_{2}$ atmosphere for $48 \mathrm{~h}$. Luciferase activity was determined by adding LightSwitch Luciferase Assay Reagent ${ }^{\text {TiN }}$ (Active Motif) according to manufacturer's protocol, and measuring the luminescence in a Synergy $\mathrm{y}^{\mathrm{TM}}$ HT Multi-Detection microplate reader (BioTek Instruments, Inc., Winooski, VT, USA). The results were recorded as the fold of the induction of the reporter plasmid in the presence of TGF- $\beta 1$, subsequent to normalization with the transfection controls without TGF- $\beta 1$ treatment.

In vitro invasion assay. The in vitro invasion assay was performed using polycarbonate $8 \mu \mathrm{M}$-pore Multiscreen MIC 96-well pre-coated with $5 \mu \mathrm{g} / \mathrm{ml}$ Matrigel (BD Biosciences). A total of $5 \times 10^{4} \mathrm{HeLa}$ cells/well were pre-treated for $24 \mathrm{~h}$ with cytokines in serum-free DMEM and then transferred to the upper wells of the filter plate. DMEM culture medium containing $10 \%$ FBS was added to the lower chambers. After $48 \mathrm{~h}$ incubation at $37^{\circ} \mathrm{C}$ in a $5 \% \mathrm{CO}_{2}$ incubator, the number of invaded cells in the bottom wells were measured using a CyQUANT ${ }^{\circledR}$ Cell Proliferation Assay kit (Molecular Probes; Thermo Fisher Scientific, Inc.); fluorescence (excitation at $450 \mathrm{~nm}$ and emission at $530 \mathrm{~nm}$ ) was measured using a Biotech K-40 spectrofluorometer (BioTek Instruments). Cells in triplicate wells without Transwell inserts served as controls for cell proliferation and/or death during the incubation period. Cell invasion was calculated from the fluorescence values as follows: Cell invasion=Relative fluorescence value of invaded cells/total cells plated in upper chamber without Transwell insert.

Statistical analysis. All experiments were performed at least 3 times with 3-5 replicates per experiment. The differences in the mean values among the groups were determined by one-way analysis of variance, and differences between individual by a Dunnett post-hoc test using SPSS v.18.0 software (SPSS Inc., Chicago, IL, USA). Data are presented as the mean \pm standard deviation. $\mathrm{P}<0.05$ was considered to indicate a statistically significant difference.

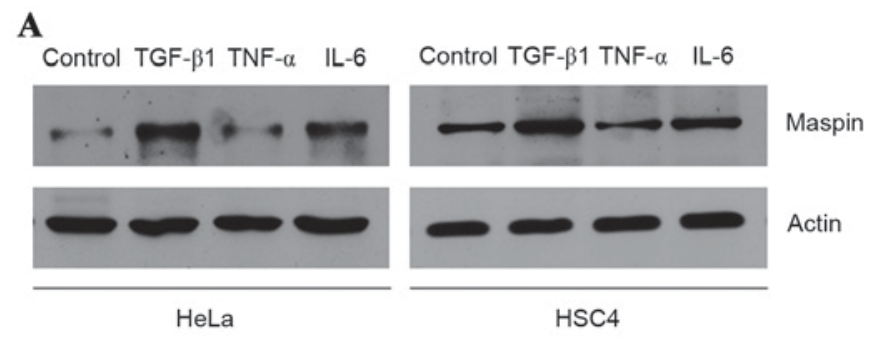

B

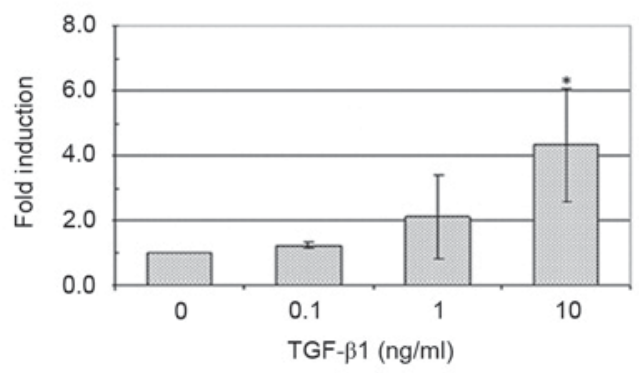

C

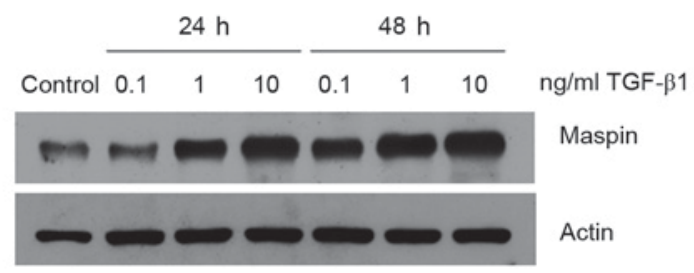

Figure 1. Induction of maspin expression by TGF- $\beta 1$ in human carcinoma cell lines. (A) Cultures of HeLa and HSC4 cells were treated with $10 \mathrm{ng} / \mathrm{ml}$ TGF- $\beta 1$, TNF- $\alpha$ or IL- 6 , and maspin expression was detected by western blot analysis following $48 \mathrm{~h}$ incubation at $37^{\circ} \mathrm{C}$. (B) HeLa cells were treated with $0.1,1$ or $10 \mathrm{ng} / \mathrm{ml} \mathrm{TGF}-\beta 1$ for $24 \mathrm{~h}$, and the levels of maspin mRNA were subsequently quantified by reverse transcription-quantitative polymerase chain reaction, using GAPDH for normalization. Results are expressed as the mean \pm standard deviation fold increase relative to untreated cells from three independent experiments. ${ }^{\text {P }}<0.05$ vs. untreated control group. (C) Maspin protein levels in HeLa cells treated with $0.1,1$ or $10 \mathrm{ng} / \mathrm{ml} \mathrm{TGF}-\beta 1$ for 24 or $48 \mathrm{~h}$ were determined by western blotting. Actin was used for normalization of gel loading. TGF- $\beta 1$, transforming growth factor $\beta 1$; TNF- $\alpha$, tumor necrosis factor $\alpha$; IL-6, interleukin-6.

\section{Results}

Effect of pro-inflammatory cytokines on maspin expression in HeLa and HSC4 cell lines. The effects of TGF- $\beta 1$, TNF- $\alpha$ and IL- 6 on maspin gene expression were evaluated in two human cancer cell lines: HeLa cervical carcinoma cells and HSC4 oral squamous cell carcinoma cells. TGF- $\beta 1$ treatment at a concentration of $10 \mathrm{ng} / \mathrm{ml}$ induced an increase in the expression levels of maspin in HeLa and HSC4 cells (Fig. 1A). By contrast, $10 \mathrm{ng} / \mathrm{ml} \mathrm{IL-6} \mathrm{exhibited} \mathrm{no} \mathrm{effect,} \mathrm{and} 10 \mathrm{ng} / \mathrm{ml}$ TNF- $\alpha$ demonstrated a slight inhibitory effect on maspin levels in the two cell lines. In the HeLa cells, $0.1-10 \mathrm{ng} / \mathrm{ml}$ TGF- $\beta 1$ treatment increased maspin gene expression levels at 24 and $48 \mathrm{~h}$. in a dose-dependent fashion compared with control cells, and this effect was demonstrated at the mRNA (Fig. 1B) and protein levels (Fig. 1C). Similar effects were observed with HSC4 cells (data not shown).

Convergence of Smad and non-Smad signaling pathways in TGF-ß1-induced maspin gene expression in HeLa cells. As expected, TGF- $\beta 1$-treated HeLa cells produced phospho-Smad2, and the presence of SIS3, a specific inhibitor 
A

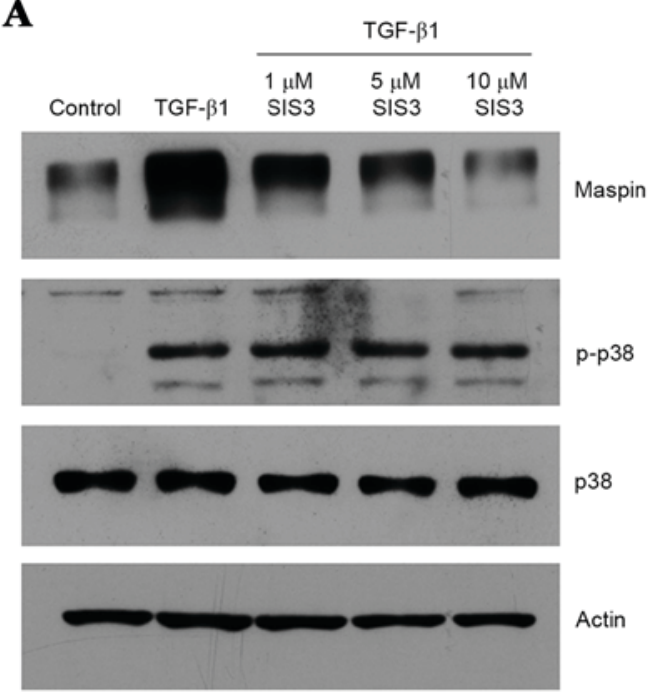

B
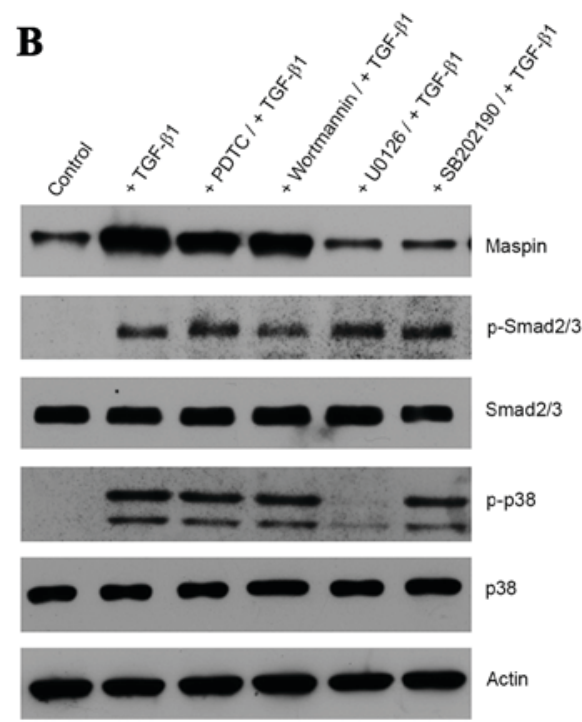

Figure 2. Induction of maspin expression through Smad and non-Smad signaling pathways. (A) Cultures of HeLa cells were pre-treated with 1,5 or $10 \mu \mathrm{M}$ SIS3 prior to the addition of $10 \mathrm{ng} / \mathrm{ml}$ TGF- $\beta 1$ and a 48 -h incubation. Maspin, p38 and p-p38 proteins were detected by western blotting. (B) HeLa cells were incubated with $100 \mu \mathrm{M}$ PDTC, $1 \mu \mathrm{M}$ wortmannin, $10 \mu \mathrm{M} \mathrm{SP} 600125,10 \mu \mathrm{M}$ U0126 or $10 \mu \mathrm{M} \mathrm{SB} 202190$ for $1 \mathrm{~h}$ at $37^{\circ} \mathrm{C}$ prior to the addition of $10 \mathrm{ng} / \mathrm{ml}$ TGF- $\beta 1$, and then further incubated for $48 \mathrm{~h}$. Maspin, p-Smad2, Smad2, p-p38 and p38 were detected by western blotting. Actin was used for normalization of gel loading. Smad, mothers against decapentaplegic homolog; SIS3, Smad3 inhibitor; TGF- $\beta 1$, transforming growth factor $\beta 1$; p-p38, phospho-p38; p-Smad2, phospho-Smad2; PDTC, pyrrolidine dithiocarbamate.

of Smad3 (21), inhibited the induction of maspin gene expression in a dose-dependent manner (Fig. 2A). It is notable that the inhibition of TGF- $\beta 1$ signaling via the Smad pathway by SIS3 did not interfere with the non-Smad pathway, as demonstrated by the presence of phospho-p38 MAPK (Fig. 2A). In order to determine whether the non-Smad signaling pathway was also activated by TGF- $\beta 1$, a series of kinase inhibitors, including PDTC (a nuclear factor $\mathrm{kB}$ inhibitor), wortmannin (a PI3K inhibitor), SP600125 (a JNK inhibitor), U0126 (a MEK1/2 inhibitor) and SB202190 (a p38 MAPK inhibitor), were employed. U0126 and SB202190 were effective in inhibiting the TGF- $\beta 1$-induced maspin gene expression, whereas PDTC, wortmannin or SP600125 were not (Fig. 2B). Inhibition by U0126 of MEK1/2, an upstream activator of p38 MAPK, resulted in an absence of p38 MAPK phosphorylation, whereas SB202190 exhibited no effect on p38 MAPK phosphorylation, as the inhibitor only binds to the ATP pocket of p38 and blocks its intrinsic ATPase activity (22). Additionally, TGF- $\beta 1$-dependent Smad2 phosphorylation was not affected by the presence of these kinase inhibitors (Fig. 2B). Taken together, these data suggest that Smad and non-Smad signaling pathways are involved in TGF- $\beta 1$-induced maspin gene expression in HeLa cells. Notably, the blockage of TGF- $\beta 1$-induced maspin expression was achieved by inhibiting one pathway without affecting the activation of the other.

TGF-ß1-induced maspin gene expression in HeLa cells requires p53-binding sites in the maspin promoter. The maspin promoter region contains two p53-binding sites, p53 I and p53 II, which are located within the first upstream 300 nucleotides (nt) (Fig. 3A). Using luciferase reporter plasmid constructs, which contain point mutations in maspin promoter p53-binding sites that have been previously demonstrated to abolish p53 protein binding (18), transfection of HeLa cells and subsequent addition of TGF- $\beta 1$ revealed that mutations in either the p53 I or p53 II binding sites significantly diminished the ability of TGF- $\beta 1$ to induce luciferase activity compared with control cells transfected with a construct containing the full-length maspin promoter sequence (nt -872 to +193 ) (Fig. 3B). Therefore, the two p53-binding sites in the maspin promoter are necessary and probably sufficient in HeLa cells for TGF- $\beta 1$-induced maspin gene expression, as the luciferase expression plasmid containing $5^{\prime}$ truncated maspin promoter element (from nt -600 or -300 to -872 ) expressed luciferase activity comparable with the cells containing the full length maspin promoter sequence (Fig. 3B).

Effect of TGF- $\beta 1$ on in vitro invasion of HeLa cells. The biological activities of maspin involve the inhibition of carcinoma cell migration and invasion (23). As incubation with TGF- $\beta 1$ upregulated the expression of maspin in HeLa cells, whether this inhibits the invasive ability of HeLa cells was examined using a Matrigel invasion assay. Notably, $10 \mathrm{ng} / \mathrm{ml}$ TGF- $\beta 1$ significantly increased the invasiveness of HeLa cells compared with the untreated control (Fig. 4).

\section{Discussion}

The present study demonstrated that TGF- $\beta 1$, but not TNF- $\alpha$ or IL-6, induced maspin gene expression at the mRNA and protein levels in cervical carcinoma HeLa and oral squamous carcinoma HSC4 cell lines. In the HeLa cells, TGF- $\beta 1$ was able to induce maspin expression through the Smad-dependent and -independent pathways.

Wang et al (18) suggested that the TGF- $\beta 1$ induction of maspin gene transcription, which occurs within $1 \mathrm{~h}$ following the addition of TGF- $\beta 1$, acts exclusively through the Smad signaling pathway and depends on p53 and Smad2/3 binding to the maspin promoter in normal mammary epithelial cells. However, in their study, p53 binding to maspin promoter was 
A 872 ATGAAGAAGCTGTGGGAAGACAGGAGGACAAGAACAGGCTCCACGAAGAGATTT CAGAGCAGAGCTGCGTACTCCTTTTTCTTTTTGTTTCTTTTGCTCTGTCACCCAGGCTGA AGTACAGTGGTTAGCTCACGGCTCACTGCAGCTTTGACCTCCCAGGCTCAAGTGATCC TCTCGTCTCAGCTTTCCAAGTAACTGGGACCACAGGCATGCATCACCACACTAGGCTAT TGTTTTACATTTTTTGTAGAGATGGGGTCTCACCATGTTGCCCAGGTTGGTCTCAAACTC CTGGGCTCAAGCAATCCGCTCACGTCAACCTCCCCAAATGCTGGGATTACAGGCGTGA GCCACCGCGCCAGGCCTGAGTAATCCTAATCACAGGATTTTAAAAAGAAACTTCCTGCG CCACCCATTAAACAATATCTCCTACCAATTTGGTAGTAAATATTTTGCTAATAGTACCTAA TTTTTAGGTAGGCACTGTGITTATACATATATCCATTCCTTCTTTTTTGATTGTCTTTCTG TITAATGGGCAGCTACCTCTCTTGGCATCTAGCAGAATGAGCTGCTGCAGTTTACACAA SBEI SBEII

AAAGAATGGAGATCAGAGTACTTTTIGTGCCACCAACGTGTCTGAGAAATTTGTAGTGT TACTATCATCACACATTACTTTTATTTCATCGAATATTTCACCTTCCGGTCCTGCGTGGG SBEI p5311

CCGAGAGGATTGCCGTACGCATGTCTGIACGTATGCATGTAACTCACAGCCCCTTCCT p531 SBEI

GCCCGAACATGTTGGAGGCCTTTTGGAAGCTGTGCAGACAACAGTAACTTCAGCCTGA

ATCATTTCTTTCAATTGTGGACAAGCTGCCAAGAGGCTTGAGTAGGAGAGGAGTGCCG CCGAGGCGGGGCGGGGCGGGGCGTGGAGCTGGGCTGGCAGTGGGCGTGGCGGTGC TGCCCAGGTGAGCCACCGCTGCTTCTGCCCAGACACGGTCGCCTCCACATCCAGGTCT TTGTGCTCCTCGCTTGCCTGTTCCTITTCCACGCATTTTCCAGGATAACTGTGACTCCA GGTAAGCAAGG +193

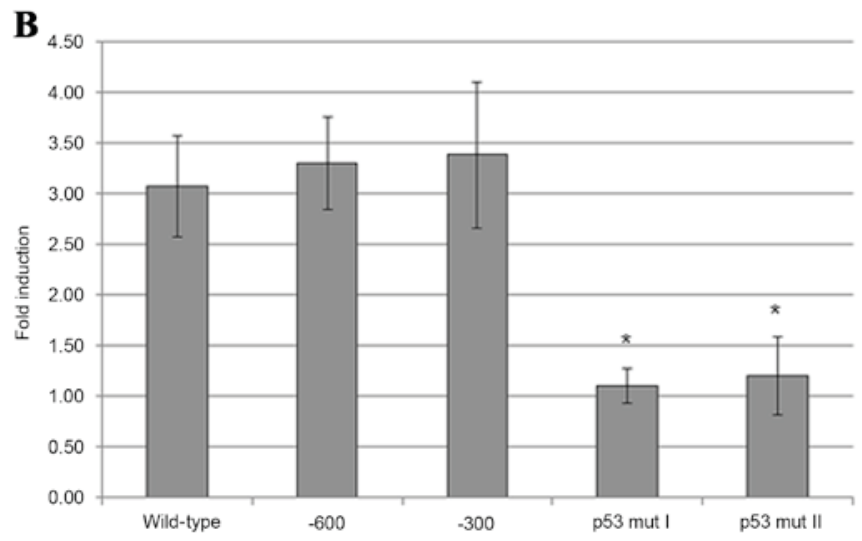

Figure 3. Requirement of p53-binding sites in maspin promoter for maspin induction by TGF- $\beta 1$ in carcinoma cells. (A) Maspin promoter sequence ranging from nucleotides -872 to +193 (wild-type), with putative Smad-binding elements (SBEI and SBEII; boxed), and the two binding sites for p53 (p53 I and p53 II; underlined). (B) HeLa cells were transfected with a luciferase reporter plasmid containing wild-type maspin promoter, two 5 truncated (-600 and -300$)$ maspin promoters, or -300 maspin promoter with point mutations in p53-binding sites, p53 mut I and p53 mut II. After $4 \mathrm{~h}$ transfection, the medium was replaced with serum-free Dulbecco's modified Eagle's medium and, after a further $2 \mathrm{~h}, 10 \mathrm{ng} / \mathrm{ml}$ TGF- $\beta 1$ was added. After $48 \mathrm{~h}$, the cells were harvested and measured by a luciferase reporter assay. Results are presented as the mean fold induction compared with the control without TGF- $\beta 1$ treatment; errors bars represent standard deviation. ${ }^{*} \mathrm{P}<0.05$ vs. -300 promoter-transfected cells. TGF- $\beta 1$, transforming growth factor $\beta 1$; $\mathrm{p} 53$, tumor protein $\mathrm{p} 53$.

detectable for $8 \mathrm{~h}$ in the absence of bound Smad2/3, suggesting the possibility of a Smad-independent TGF- $\beta 1$-induced signaling pathway of p53-dependent activation of maspin expression. Notably, one observation of the present study in HeLa cells suggested the requirement of both Smad2 and p53 promoter binding for the induction of maspin gene expression by TGF- $\beta 1$ via the non-Smad pathway. This hypothesis is concomitant with a crosstalk between the TGF- $\beta 1$ signaling pathway and p53, which has been demonstrated previously (24). Phosphorylated wild-type p53 physically interacts with the phospho-Smad2/3-Smad4 complex upon TGF- $\beta 1$ induction and in turn binds to promoters of tumor suppressive genes (25).

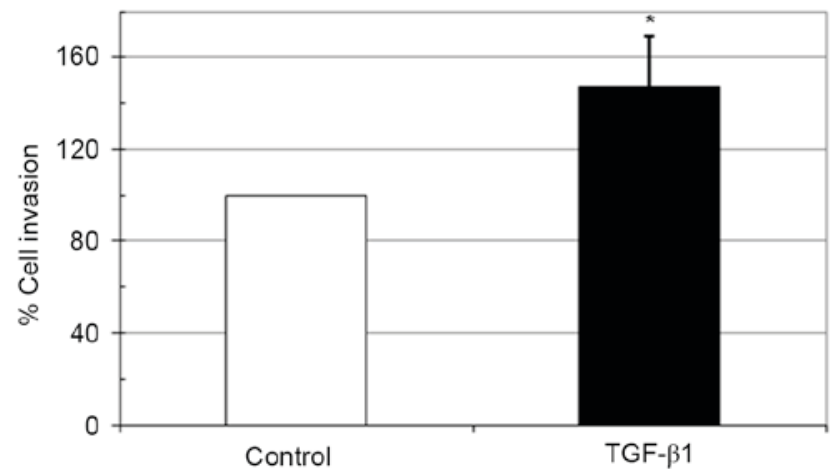

Figure 4. Effect of TGF- $\beta 1$ on HeLa cell invasion in vitro. HeLa cells were pre-treated with $10 \mathrm{ng} / \mathrm{ml} \mathrm{TGF}-\beta 1$ for $48 \mathrm{~h}$ prior to in vitro Matrigel invasion assay using a Transwell system. The $y$-axis illustrates percent cell invasion compared with untreated control. Data are presented as mean \pm standard deviation from three independent experiments. ${ }^{*} \mathrm{P}<0.05$ vs. untreated control. TGF- $\beta 1$, transforming growth factor $\beta 1$.

The non-Smad pathway acts via MEK1/2 and p38 MAPK. MEK1/2 is an upstream signaling molecule of p38 MAPK activation (26). In the present study, the inhibition of MEK1/2 and p38 MAPK in HeLa cells prevented the stimulatory effect of TGF- $\beta 1$ on maspin expression without affecting Smad phosphorylation. The phosphorylation of p53 at Ser389 by p38 MAPK increases its DNA-binding capability (27). Cordenonsi et al (28) revealed that, in H1299 human lung cancer cells, MEK1/2 inhibition by U0126 blocks the phosphorylation of $\mathrm{p} 53$, which is concomitant with the loss of TGF- $\beta 1$-induced p21 expression. The inhibition of the Smad-dependent TGF- $\beta 1$ signaling pathway by SIS3 in the present study did not interfere with the non-Smad pathway, as demonstrated by the presence of phospho-p38 MAPK. This is consistent with previous data suggesting that TGF- $\beta 1$-mediated activation of p38 MAPK signaling is independent of TGF- $\beta 1$ type I receptor-mediated Smad activation (29). Therefore, it is possible that the non-Smad TGF- $\beta 1$ pathway of maspin gene expression induction is mediated by MEK1/2 and p38 MAPK phosphorylation of p53, which promotes p53 binding to maspin promoter.

Hypermethylation of the maspin promoter contributes to maspin silencing in cancer cells (30). Previously, TGF- $\beta 1$ was not observed to have an effect on maspin expression in a number of cancer cell lines, including the mammary carcinoma cell line MDA-MB-231 which has mutant p53 and maspin promoter hypermethylation (18). In maspin-expressing transformed cells, including MCF10A, the maspin promoter is hypomethylated (31). The present study also identified hypomethylated maspin promoters in HeLa cells (data not shown).

TGF- $\beta 1$ may induce the migration and invasion of several types of carcinoma cells via the activation of the PI3K and Akt pathway (32). In the present study, a similar event, in which TGF- $\beta 1$ stimulated the migration and invasion of HeLa cells, was observed. Although maspin has been demonstrated to inhibit cancer cell motility and invasiveness (33), in HeLa cells the TGF- $\beta 1$-induced increase in maspin levels was apparently not sufficient to attenuate the cancer cell migration and invasion properties mediated by TGF- $\beta 1$. Despite the tumor suppressive activities of maspin in numerous types of cancer cells, a paradoxical increase of maspin expression has 
been identified in several malignant cell types compared with their normal cells of origin, including those from lung (34), bladder (35), and ovarian tissues (36). An upregulation of maspin expression is also associated with the advanced stages of several types of tumors, including tumors of the cervix (37), endometrium (38), and pancreas (9). In addition, the subcellular localization of maspin may serve a critical role in its biological function. For example, the nuclear localization in cancer cells is essential for the tumor suppressor activity of maspin (39). In addition, an increased cytoplasmic localization of maspin was revealed in an invasive SKOV3 cell line, but any tumor suppressive activity may have been inactivated, as the invasion capabilities were not affected by a blocking antibody (7). Therefore, TGF- $\beta 1$-induced maspin expression may not be able to inhibit tumor invasion and may serve a role in cancer progression.

In conclusion, the present study demonstrated the increased expression of maspin induced by TGF- $\beta 1$ in human cervical carcinoma HeLa and oral squamous carcinoma HSC4 cell lines. The results indicated that the upregulation of maspin expression was due to Smad and non-Smad MEK/MAPK TGF- $\beta 1$ signaling pathways, acting independently but converging to promote p53 binding to the maspin promoter. However, the underlying molecular mechanisms of this phenomenon require additional study, and may provide supporting evidence for an association between the inflammatory response and cancer progression, which may lead to the development of novel cancer prevention and treatment strategies.

\section{Acknowledgements}

The present study was supported by grants from the National Research Council of Thailand (grant no. 48499), the Faculty of Medicine Research Fund of Chiang Mai University (grant no. 077/2558), the Office of the Higher Education Commission and Mahidol University under the Thailand National Research Universities Initiative and the Faculty of Dentistry of Mahidol University. The authors would like to thank Professor Prapon Wilairat (Faculty of Science, Mahidol University) for critical reading of the manuscript and useful comments.

\section{References}

1. Silverman GA, Bird PI, Carrell RW, Church FC, Coughlin PB, Gettins PG, Irving JA, Lomas DA, Luke CJ, Moyer RW, et al: The serpins are an expanding superfamily of structurally similar but functionally diverse proteins. Evolution, mechanism of inhibition, novel functions, and a revised nomenclature. J Biol Chem 276: 33293-33296, 2001.

2. Bodenstine TM, Seftor RE, Khalkhali-Ellis Z, Seftor EA, Pemberton PA and Hendrix MJ: Maspin: Molecular mechanisms and therapeutic implications. Cancer Metastasis Rev 31: 529-551, 2012.

3. Zou Z, Anisowicz A, Hendrix MJ, Thor A, Neveu M, Sheng S, Rafidi K, Seftor E and Sager R: Maspin, a serpin with tumor-suppressing activity in human mammary epithelial cells. Science 263: 526-529, 1994.

4. Beltran A, Parikh S, Liu Y, Cuevas BD, Johnson GL, Futscher BW and Blancafort P: Re-activation of a dormant tumor suppressor gene maspin by designed transcription factors. Oncogene 26: 2791-2798, 2007.

5. Maass N, Nagasaki K, Ziebart M, Mundhenke C and Jonat W: Expression and regulation of tumor suppressor gene maspin in breast cancer. Clin Breast Cancer 3: 281-287, 2002.
6. Zou Z, Zhang W, Young D, Gleave MG, Rennie P, Connell T, Connelly R, Moul J, Srivastava S and Sesterhenn I: Maspin expression profile in human prostate cancer $(\mathrm{CaP})$ and in vitro induction of Maspin expression by androgen ablation. Clin Cancer Res 8: 1172-1177, 2002.

7. Bauerschlag DO, Habermann M, Weimer J, Meinhold-Heerlein I, Hilpert F, Weigel M, Bauer M, Mundhenke C, Jonat W, Maass $\mathrm{N}$ and Schem C: Heterogeneous expression of serine protease inhibitor maspin in ovarian cancer. Anticancer Res 30: 2739-2744, 2010.

8. Frey A, Soubani AO, Adam AK, Sheng S, Pass HI and Lonardo F: Nuclear, compared with combined nuclear and cytoplasmic expression of maspin, is linked in lung adenocarcinoma to reduced VEGF-A levels and in Stage I, improved survival. Histopathology 54: 590-597, 2009.

9. Liu H, Shi J, Anandan V, Wang HL, Diehl D, Blansfield J, Gerhard G and Lin F: Reevaluation and identification of the best immunohistochemical panel (pVHL, Maspin, S100P, IMP-3) for ductal adenocarcinoma of the pancreas. Arch Pathol Lab Med 136: 601-609, 2012.

10. Cao D, Wilentz RE, Abbruzzese JL, Ho L and Maitra A: Aberrant expression of maspin in idiopathic inflammatory bowel disease is associated with disease activity and neoplastic transformation. Int J Gastrointest Cancer 36: 39-46, 2005.

11. Kim J, Jang KT, Kim KH, Park JW, Chang BJ, Lee KH, Lee JK, Heo JS, Choi SH, Choi DW, et al: Aberrant maspin expression is involved in early carcinogenesis of gallbladder cancer. Tumour Biol 31: 471-476, 2010.

12. Dinarello CA: The paradox of pro-inflammatory cytokines in cancer. Cancer Metastasis Rev 25: 307-313, 2006.

13. Gohji K, Nomi M, Hara I, Arakawa S and Kamidono S: Influence of cytokines and growth factors on matrix metalloproteinase-2 production and invasion of human renal cancer. Urol Res 26: 33-37, 1998.

14. Heldin CH and Moustakas A: Role of Smads in TGFb signaling. Cell Tissue Res 347: 21-36, 2012.

15. Mu Y, Gudey SK and Landström M: Non-Smad signaling pathways. Cell Tissue Res 347: 11-20, 2012.

16. Arteaga CL, Dugger TC and Hurd SD: The multifunctional role of transforming growth factor (TGF)-beta s on mammary epithelial cell biology. Breast Cancer Res Treat 38: 49-56, 1996.

17. Drabsch Y and ten Dijke P: TGF-b signaling in breast cancer cell invasion and bone metastasis. J Mammary Gland Biol Neoplasia 16: 97-108, 2011.

18. Wang SE, Narasanna A, Whitell CW, Wu FY, Friedman DB and Arteaga CL: Convergence of $\mathrm{p} 53$ and transforming growth factor beta (TGFbeta) signaling on activating expression of the tumor suppressor gene maspin in mammary epithelial cells. J Biol Chem 282: 5661-5669, 2007.

19. Livak KJ and Schmittgen TD: Analysis of relative gene expression data using real-time quantitative PCR and the 2(-Delta Delta C(T)) Method. Methods 25: 402-408, 2001.

20. Jung V, Pestka SB and Pestka S: Cloning of polymerase chain reaction-generated DNA containing terminal restriction endonuclease recognition sites. Methods Enzymol 218: 357-362, 1993.

21. Jinnin M, Ihn H and Tamaki K: Characterization of SIS3, a novel specific inhibitor of Smad3, and its effect on transforming growth factor-beta1-induced extracellular matrix expression. Mol Pharmacol 69: 597-607, 2006.

22. Kumar S, Jiang MS, Adams JL and Lee JC: Pyridinylimidazole compound SB 203580 inhibits the activity but not the activation of p38 mitogen-activated protein kinase. Biochem Biophys Res Commun 263: 825-831, 1999.

23. Bailey CM, Khalkhali-Ellis Z, Seftor EA and Hendrix MJ: Biological functions of maspin. J Cell Physiol 209: 617-624, 2006.

24. Elston R and Inman GJ: Crosstalk between p53 and TGF-beta Signalling. J Signal Transduct 2012: 294097, 2012.

25. Cordenonsi M, Dupont S, Maretto S, Insinga A, Imbriano C and Piccolo S: Links between tumor suppressors: p53 is required for TGF-beta gene responses by cooperating with Smads. Cell 113: 301-314, 2003.

26. Poddar R and Paul S: Novel crosstalk between ERK MAPK and p38 MAPK leads to homocysteine-NMDA receptor-mediated neuronal cell death. J Neurochem 124: 558-570, 2013.

27. Huang C, Ma WY, Maxiner A, Sun Y and Dong Z: p38 kinase mediates UV-induced phosphorylation of p53 protein at serine 389. J Biol Chem 274: 12229-12235, 1999. 
28. Cordenonsi M, Montagner M, Adorno M, Zacchigna L, Martello G, Mamidi A, Soligo S, Dupont S and Piccolo S: Integration of TGF-beta and Ras/MAPK signaling through p53 phosphorylation. Science 315: 840-843, 2007.

29. Yu L, Hebert MC and Zhang YE: TGF-beta receptor-activated p38 MAP kinase mediates Smad-independent TGF-beta responses. EMBO J 21: 3749-3759, 2002.

30. Oshiro MM, Watts GS, Wozniak RJ, Junk DJ, MunozRodriguez JL, Domann FE and Futscher BW: Mutant p53 and aberrant cytosine methylation cooperate to silence gene expression. Oncogene 22: 3624-3634, 2003.

31. Horswill MA, Narayan M, Warejcka DJ, Cirillo LA and Twining SS: Epigenetic silencing of maspin expression occurs early in the conversion of keratocytes to fibroblasts. Exp Eye Res 86: 586-600, 2008.

32. Vo BT, Morton D Jr, Komaragiri S, Millena AC, Leath C and Khan SA: TGF-b effects on prostate cancer cell migration and invasion are mediated by PGE2 through activation of PI3K/AKT/mTOR pathway. Endocrinology 154: 1768-1779, 2013.

33. Ngamkitidechakul C, Warejcka DJ, Burke JM, O'Brien WJ and Twining SS: Sufficiency of the reactive site loop of maspin for induction of cell-matrix adhesion and inhibition of cell invasion. Conversion of ovalbumin to a maspin-like molecule. J Biol Chem 278: 31796-31806, 2003.
34. Yatabe Y, Mitsudomi T and Takahashi T: Maspin expression in normal lung and non-small-cell lung cancers: Cellular property-associated expression under the control of promoter DNA methylation. Oncogene 23: 4041-4049, 2004.

35. Friedrich MG, Toma MI, Petri S, Cheng JC, Hammerer P, Erbersdobler A and Huland $\mathrm{H}$ : Expression of Maspin in non-muscle invasive bladder carcinoma: Correlation with tumor angiogenesis and prognosis. Eur Urol 45: 737-743, 2004.

36. Rose SL, Fitzgerald MP, White NO, Hitchler MJ, Futscher BW, De Geest $\mathrm{K}$ and Domann FE: Epigenetic regulation of maspin expression in human ovarian carcinoma cells. Gynecol Oncol 102: 319-324, 2006.

37. Nosaka K, Horie Y, Shiomi T, Itamochi H, Oishi T, Shimada M, Sato S, Sakabe T, Harada T and Umekita Y: Cytoplasmic maspin expression correlates with poor prognosis of patients with adenocarcinoma of the uterine cervix. Yonago Acta Med 58: 151-156, 2015.

38. Torres A, Torres K, Paszkowski T, Radej S, Staśkiewicz GJ, Ceccaroni M, Pesci A and Maciejewski R: Highly increased maspin expression corresponds with up-regulation of miR-21 in endometrial cancer: A preliminary report. Int J Gynecol Cancer 21: 8-14, 2011.

39. Goulet B, Kennette W, Ablack A, Postenka CO, Hague MN, Mymryk JS, Tuck AB, Giguère V, Chambers AF and Lewis JD: Nuclear localization of maspin is essential for its inhibition of tumor growth and metastasis. Lab Invest 91: 1181-1187, 2011. 